\title{
The Relationship Between High School GPA and Information Literacy Pre and Post-Test Scores
}

\section{Eric Shannon}

\section{Keene State College}

\begin{abstract}
Although many studies explore the effect of library instruction on information literacy test scores, there are far fewer studies exploring the relationship between high school Grade Point Average (GPA) and scores on information literacy pre- and post-tests of first year college students. This research study compares the scores of three cohorts of Franklin Pierce University students--honors students, Center Scholars (students with a cumulative high school GPA of below 2.5) and Average GPA students -on an information literacy pre-test administered in the first two weeks of the fall, and a similar posttest administered after students have attended a library instruction session. The results of this study show a relationship between high school GPA and pre-test scores and reveal an even stronger relationship between high school GPA and scores on the post-test, with honors students attaining the highest scores and Center Scholars the lowest. This article proposes explanations for these results as well as recommendations for addressing the test score disparities between these three cohorts.
\end{abstract}

Keywords: information literacy, assessment, high school gpa, library instruction

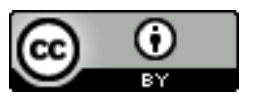

This is an Open Access article distributed under the terms of the Creative Commons Attribution 4.0 International License (http://creativecommons.org/licenses/by/4.0), which permits unrestricted use, distribution, and reproduction in any medium, provided the original work is properly cited. 


\section{Introduction}

\section{Franklin Pierce Overview}

Franklin Pierce University is primarily a residential undergraduate college. Our residential undergraduate campus, known as the College at Rindge, is a small, rural liberal arts college in southwestern New Hampshire. As of June 1, 2019, our full-time undergraduate enrollment is currently 1,455 students. All incoming freshmen at Franklin Pierce are required to take First Year Inquiry (FYI). FYI is designed to introduce students to college level research, to help students acclimate to college life, and to provide them the opportunity to explore possible career opportunities. Professors in the FYI program pick different themes and readings for their respective classes; each section, regardless of theme, works on improving students' academic skills and addresses three learning outcomes information literacy, inquiry and analysis, and career exploration. FYI classes have required common assignments including a multi-part research project, typically culminating in an annotated bibliography and poster presentation. Although incoming first year class sizes have varied from 452 for the 2015-16 academic year to 652 for the 2016-2017 academic year, sections of FYI are kept to around 19 students per class.

All sections of FYI are strongly encouraged to bring their students to at least one library instruction session. This library one-shot session was designed by librarians in collaboration with the FYI coordinator with two main purposes: to introduce students to the physical library space and librarians, and to assist students with their FYI research projects. In the summer of 2014, librarians met with the FYI coordinator in order to devise a session that would meet the information literacy goals of the FYI class. The FYI coordinator wanted to make sure that the required library session would provide students a basic familiarity with using library sources in order to conduct research. Some sections of FYI bring students in for a second session to learn higher order skills such as source evaluation, but 
since many do not, we wanted to make sure that all first year students at least received a basic introduction to academic research. With this in mind, the FYl library one-shot session teaches students basic foundational research skills. In class, librarians use a libguide (see Appendix A) created specifically for this one shot session to help students complete a worksheet in which they write down their inquiry question, develop a list of keyword terms, and perform simple keyword searches in both the library catalog and the database Academic Search Complete. Students and FYI professors can revisit the libguide in order to refresh the content covered. As a small college library, there are only two librarians who teach these one-shot sessions, the Reference and Instruction Librarian, and the Electronic Resources Librarian.

Librarians and FYI professors alike observed that although the library instruction session improved students' basic research skills, there were still wide discrepancies in students' abilities to navigate the library website and find relevant books and articles. In order to get a clearer sense of first year students' library knowledge and searching skills, in the Spring of 2015, librarians at Franklin Pierce devised a library pre-test and post-test that assessed students' knowledge of basic library and searching skills. The pre-test would be administered during the first two weeks of the fall semester and the post-test would be administered at the end of the fall semester after students had attended a library instruction session with their FYI class. In addition to gaining knowledge about the research skills of first year Franklin Pierce students as a whole, we wanted to dig deeper and see if there were disparities in the research skills of students based on their incoming high school GPAs. This research study compares the scores of three cohorts of Franklin Pierce University students--honors students, Center Scholars, and Average GPA students. The first-year information literacy pre and post-tests were approved by the IRB in the summer of 2015, with testing beginning during the fall 2015 semester. This study uses data gathered from the fall 2015, 2016, and 2017 semesters. 


\section{Center Scholar Program at Franklin Pierce}

The Center Scholar program at Franklin Pierce was developed in the Fall of 2014 in order to improve the retention rate of students who enter with low high school GPAs. Typically, between 25 and 30 percent of incoming first year students are designated as Center Scholars. An analysis of the retention rates for various students at Franklin Pierce showed that those who entered with a GPA of 2.5 or below only retained at a rate of 52 percent while the retention rate for all other students was consistently around 75 percent.

Center Scholar program is overseen by the Center for Academic Excellence (CAE), which provides academic and time management counseling to students. Center Scholar status includes a $\$ 1,000$ scholarship toward annual tuition, provided that the student maintains a minimum 2.0 (on a 4.0 scale) cumulative GPA. In addition, Center Scholars must attend two individual appointments per semester with a CAE staff member, a Wensberg Writing Center tutor, or a peer tutor, and three additional individual meetings and/or workshops per semester.

According to academic advisors in the CAE who work with Center Scholars, these students often struggle the most with executive functioning skills, which are a set of processes used in the control and regulation of behavior and the selection and monitoring of behaviors that assist in the attainment of chosen goals (Barkley, 2012). These executive functioning problems regularly manifest in the form of poor attendance, time management skills, planning, assignment completion, and an inability to pay attention in class

Center Scholars arrive on campus at the same time as other students, attend the same orientation sessions, live in the same dormitories, and are placed in the same sections of First Year Inquiry as the rest of the student body. (CGPA). Although some Center Scholars must take remedial math and are placed into a Composition I section that has a writing tutor and more systems of support, 
many Center Scholars (those with incoming GPAs of 2.0 or higher who have tested out of Math Skills and the tutored section of Composition I) are fully integrated into all of their classes with the rest of the student body.

\section{The Honors Program at Franklin Pierce}

The Honors program was created in order to provide more challenging classes for students. Admission into the Honors Program as a first-year student is contingent upon students obtaining a minimum of a 3.4 high school GPA and taking a minimum of three honors or Advanced Placement classes. Students in the Honors Program typically take an honors section of both First Year Inquiry and Composition I in the fall and II in the spring semester (although some may be in the general sections due to scheduling conflicts). The honors sections are typically smaller, require more reading, and longer writing assignments than the other sections. Successful completion of the Honors Program requires a cumulative grade point average of 3.40 or higher and completion of seven honors courses (18 or more credits), at least two of which are at the 300-or 400-level.

\section{“Average GPA" Students}

Average GPA students is the term that we are using to describe students who are neither in the Honors program nor the Center Scholars program. The median high school GPA for all incoming first year students (including both honors students and Center Scholars) is typically around 2.8. Eighty percent of our students come from New England states with a plurality of thirty-eight percent of our student body currently hailing from Massachusetts.

\section{Literature Review}

Although literature looking at the impact of high school GPA on information literacy assessment is sparse, there have been some articles published that delve into the topic. Geffert and Christensen's (1998) study The Things They Carry describes a survey of incoming first year students at 
St. Olaf College completed in 1996. The survey that students were given included a test of basic skills and general knowledge including Boolean operators, the scope of subject headings, citation formats, and distinctions between primary and secondary sources. The authors examined many variables including high school GPA, size of graduating class, exposure to research and libraries, expected major, number of books read over the summer, and hours of TV watched per week. This study found a clear correlation between having a high high school GPA (3.4 or higher) and scoring well on the test. This study also found that students with high GPAs were more likely to enjoy unstructured time in the library, believe that material found on the internet is less reliable than material found in academic libraries, have used ILL, have cited more sources in high school research papers, have used news groups, and are female (Geffert \& Christiansen, 1998). Although this study provides some interesting insights regarding the relationship between high school GPA and performance on an information literacy test, the assessment that was used tested students on several concepts that were more advanced than what we tested our students on and took place over twenty years ago. This assessment also did not include a post-test to measure students' progression at the end of the semester.

Nearly a decade later, Gross and Latham (2007) conducted research that used the Information Literacy Test (ILT) to analyze the top $25 \%$ and bottom $25 \%$ of the incoming class based on high school GPA and SAT/ACT scores. Although this study focused on the relationship between students' actual information literacy skill level and their self-estimates of skill, their findings also revealed differences in the information literacy skills of high and low GPA incoming college students. The mean score for bottom tier students on the ILT was 33.94 while the mean score for top tier students was 42.15 indicating a significant difference between the information literacy skills of these two groups (Gross \& Latham, 2007). Like Geffert and Christiansen's (1998) study, however, this research project did not include a post-test to measure the effects of library instruction on test scores. 
Other articles discussing the relationship between high school GPA and scores on information literacy tests include Fabbi's (2015) and Lanning and Malek's (2017) studies. Fabbi's article discusses the scores of first year students at The University of Nevada Las Vegas who took the iSkills assessment, a standardized test developed by Educational Testing Services that was used to gauge students' digital information literacy skills. Fabbi's research found that cumulative core high school GPA and curricular track were strong predictors of iSkills scores (Fabbi, 2015). Lanning and Malek's article discusses the scores of first year students enrolled in an eight-week information literacy class, who took a pre-test prior to enrolling in the class and a post-test at the culmination of the course. They analyzed multiple factors including high school GPA, current college GPA, ACT scores, high school enrollment, per capita income, and educational attainment of the parents. Their analysis of students' scores revealed that ACT scores and current college GPA were the primary factors influencing scores on both the pre and post-tests (Lanning \& Malek, 2017).

Although research specifically related to high school GPA is limited, there are many studies that explore the effect of information literacy instruction on student academic success. Several large-scale studies have shown a positive correlation between library instruction and college GPA. A study that evaluated over 8,000 undergraduate and graduate transcripts at Hong Kong Baptist University found a positive correlation between exposure to multiple library instruction workshops and higher GPA (Wong \& Cmor, 2011). This study demonstrated that library instruction has a direct impact on student success, but only if three or more library sessions are offered within a program.

A 2013 study similarly found a statistically significant relationship between students' GPA at graduation and upper-division library instruction (Mayer, J., \& Bowles-Terry). This study looked at three student cohorts: students who received upper-level library instruction, students who received only freshman-level instruction, and students who received no library instruction at all. Their findings show 
that students who receive upper-level instruction at the library have higher GPAs, while there is no significant difference in GPA for students who have only freshman-level library instruction.

A 2018 study of 1,380 students who graduated from St Mary's College between 2012 and 2015, looked at the number of courses those students were enrolled in that had a library instruction session and their respective four-year GPAs. This study found a statistically significant increase in the GPAs of students who were enrolled in at least one class with a library instruction session (Gaha et. al).

While these studies provide valuable insight on the positive effect that library instruction can have on student academic success, they do not attempt to analyze whether or not students respond more favorably to library instruction based on their incoming high school GPA. Gaining an understanding of the possible barriers to learning that students with low high school GPAs face is an important goal of this study.

Current research shows that students with low high school GPAs often have non-cognitive attributes that affect their abilities to learn. A 2014 research article by Knouse, Feldman and Blevins titled Executive functioning difficulties as predictors of academic performance: Examining the role of grade goals discussed the results of two studies that explored the relationship between executive functioning deficits among college students and GPA. Using the Barkley Deficits in Executive Functioning Scale (BDEFS), a 20 item self-report measure of executive functioning, and self-reported GPA, the first study found that executive functioning deficits were associated with academic performance of college students. The subscale of the BDEFS that showed the strongest and most consistent negative association with GPA was the scale measuring self-motivation problems. Selforganization and problem-solving deficits were also negatively associated with GPA (Knouse et al).

The second study used grade data obtained from the registrar in order to evaluate the association of the BDEFS subscales with GPA. This study specifically examined goal setting as a 
potential mediator of the effects of self-motivation problems. The researchers found that deficits in time management and self-motivation were significantly associated with GPA. Additionally, they found that students with greater self-motivation deficits both set lower goals and achieved lower GPAs (Knouse et al). The executive functioning deficits exhibited by these students are consistent with the motivational and planning issues that CAE advisors have observed when working with Center Scholars.

A 2007 study by Hsieh, Sullivan and Guerra titled A Closer Look at College Students: SelfEfficacy and Goal Orientation also explored the non-cognitive attributes that contribute to academic success at the collegiate level. Their study found that students in good academic standing had higher self-efficacy (defined as students' judgements about their abilities to complete a task) and adopted significantly more mastery goals (defined as students' motives for completing tasks that develop and improve their abilities) than students on academic probation. Performance-avoidance goals (defined as the motivation to hide a lack of ability) on the other hand, were negatively related to academic standing (Hsieh et al., 2007).

Most of the existing research produced over the past twenty years has shown that students with higher incoming high school GPAs have also received higher scores on information literacy tests. However, minimal research has been done to examine the scores on assessments focused on foundational skills, and the improvement rate of students with different incoming GPAs on a post-test following library instruction. In addition, the articles on the topic did not focus exclusively on high school GPA as an influencing factor, but instead explored high school GPA as one of many possible factors influencing information literacy test scores. This study is focused on high school GPA, and also provides an in-depth analysis of scores on different question types. 


\section{The Library Skills Assessment}

As part of the library's efforts to improve information literacy instruction, librarians at Franklin Pierce created a rubric that delineates information literacy learning outcomes for first year students. Under the category of basic library skills, we included the ability to identify keywords, or "main concepts" of an inquiry question, find a book in the catalog and identify its call number, find an article in a database, and the ability to parse a citation (identify journal or book title, author, date). Using backward design, we devised a one-shot instruction session that seeks to provide students with these basic level information literacy skills, as well as the pre- and post- tests used to gauge the effectiveness of this instruction session. When designing the pre and post-tests, we focused on developing questions that would test students' knowledge of basic library concepts as well as their skills in navigating the library's website, using the catalog, and performing basic keyword searches in Academic Search Complete. We divided the types of questions into three categories: self-reported, general knowledge, and performance questions. The performance questions ask students to perform a task that requires them to use library resources to find the correct answer.

The self-reported category includes questions such as

- "Have you ever used a library catalog?" and

- "Have you ever used a research database?" (replaced on the post-test with "Have you used a library catalog this semester to find a book?" and "Have you used a database this semester to find an article?").

The general knowledge category includes questions such as

- "Which response best describes a research database?" and

- "An Abstract is?"

The performance category includes questions such as 
- "Using the database Academic Search Complete, search for college recycling. How many articles do you retrieve"?

- "Use the library catalog to find the book Teaching First-Year College Students. What is this book's call number?"

- The inquiry question for my research paper is, "What can colleges do to promote recycling on campus?" Please list the most important keyword terms or main concepts of my inquiry question.

Previous assessment of students' library research skills at Franklin Pierce sought to gauge students' opinions/reactions to library instruction as well as their personal self-evaluations of their own abilities, and confidence using library resources. Although these previous assessments provided good data about students opinions and self-assessments, we wanted to devise a more objective measure of students' existing knowledge upon arrival on campus and the extent to which their knowledge and abilities improve after having attended a library instruction session. In addition, research has shown that students frequently overestimate their own information literacy skills (Mahmood, 2013). When devising the assessment questions, we wanted to try to avoid affective measures that gauged students personal feelings and beliefs about their ability to conduct research, and instead limit our questions primarily to those that measured skill and knowledge.

\section{Methodology}

This study received IRB approval in the summer of 2015. IRB approval was granted again in 2016 and 2017. Prior to attending their information literacy instruction session, students in all FYI classes take the 5- to 10-minute information literacy pre-test. Librarians provide professors with the SurveyMonkey URL, but the pre-tests are administered by students' FYI instructors during their FYI class and not during the library instruction session. Toward the end of the semester, FYI professors 
again have students complete the 5 - to 10 -minute post-test. On both the pre and post-tests, students are asked to enter their Franklin Pierce ID number. After the surveys are completed, librarians send the data to our IT department who use students' ID numbers to code them as honors students or Center Scholar students. Since the assessment used a combination of question types, including self-reported responses, we did not score each student on the entire test. Instead, we divided the questions into the three categories: self reported, general knowledge, and performance, and compared scores across question types.

\section{Librarians' Hypotheses}

We had four hypotheses related to student test scores:

- Scores on the library skills pre-test would reflect students' high school GPAs with honors students receiving the highest scores across question types, followed by Average GPA students, and then Center Scholars.

- The greatest disparity in scores among the three cohorts would be on general knowledge questions.

- The smallest disparity in scores among the three cohorts would be on performance questions as all three cohorts lacked familiarity with the library's website, catalog, and databases.

- Scores would become less pronounced among the three cohorts on the post-test as the advantages held by students with higher exposure to libraries would diminish as the rest of the students gained familiarity with basic library resources and search skills. Due to the fact that the library skills pre and post-tests focus on foundational skills, we believed that Center Scholars would be able to significantly narrow the gap on honors and Average GPA students by the time they took the post-test. 


\section{Results}

\section{Participation Rate}

During the three-year testing period a total of 1,571 students entered Franklin Pierce as first year undergraduates at our Rindge campus, including 461 Center Scholars, 976 Average GPA students and 134 honors students.

\section{Pre-Test Participation Rate}

A total of 716 students completed the FYl library skills pre-test including 85 center scholars, 571 Average GPA students, and 60 honors students. $45.6 \%$ percent of all incoming first year students completed the FYI library skills pre-test. The participation rate for the test varied greatly based on high school GPA with $18.44 \%$ of Center Scholars, $58.5 \%$ of Average GPA students, and $44.78 \%$ of honors students completing the pre-test

\section{Post-Test Participation Rate}

A total of 587 students completed the post-test during the same three-year testing period including 56 Center Scholars, 64 honors students and 467 Average GPA students. 37.3\% of all incoming first-year students completed the post-test. The post-test participation rate also varied greatly based on high school GPA with $12.15 \%$ of Center Scholars, $47.85 \%$ of Average GPA students, and $47.78 \%$ of honors students completing the post-test.

Since honors students are in separate FYI classes, their participation rate is highly dependent on whether or not their FYI professor decides to administer the test to students and/or how their professor administers the test (in class, via an email link etc.) However, since Center Scholars are mixed into FYI sections with the rest of the student body, their low completion rate of the pre and post-tests cannot be explained by how their FYI professor administered the test. Center for Academic Excellence advisors who work specifically with the Center Scholar cohort have noted that Center Scholars also 
have a lower attendance and homework completion rate compared to students' Average GPA and honors students.

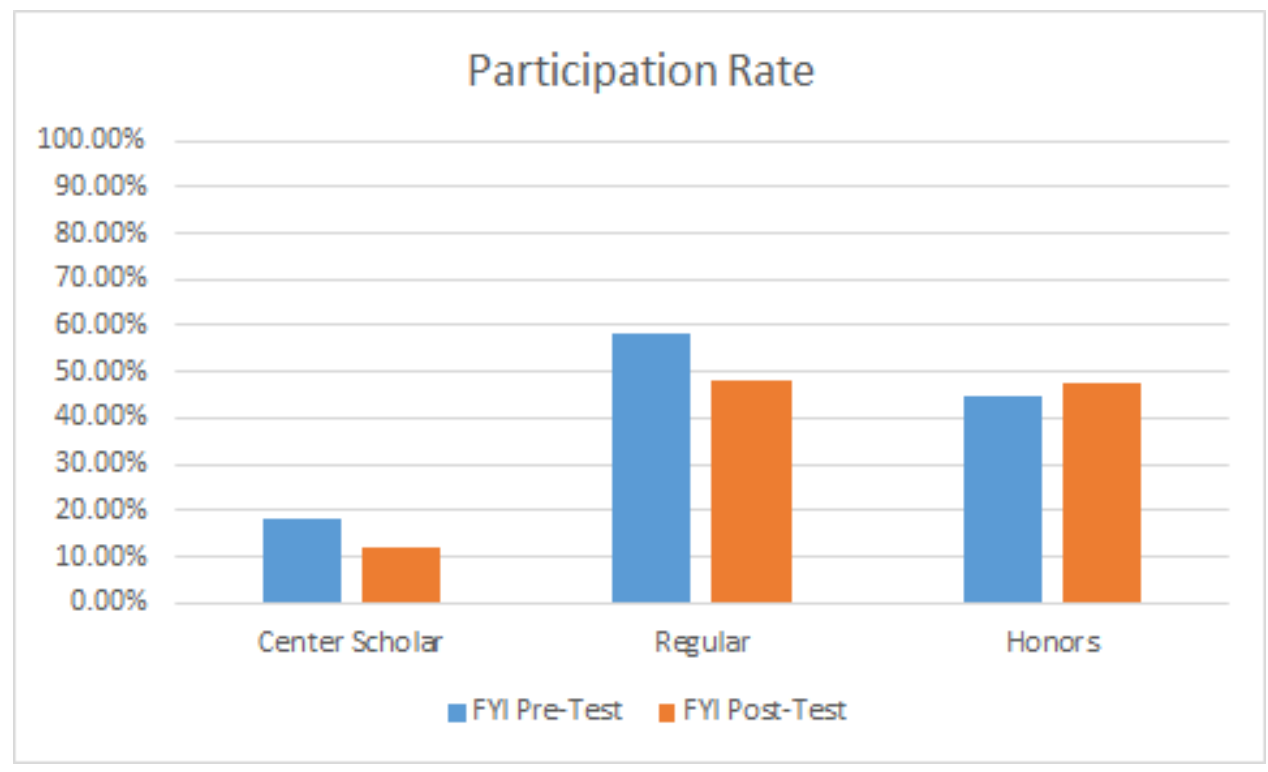

Figure 1. Participation rate

\section{Pre-Test Scores: Self-Reported Responses}

Two questions of the pre-test were categorized as self-reported responses including "Have you ever used a library catalog?" and "Have you ever used a research database?" $41.6 \%$ of all students reported having used a library catalog including $41.2 \%$ of Center Scholars, $41.3 \%$ of Average GPA students and $45 \%$ of honors students. $80.6 \%$ of all students reported having used a research database, including $82.4 \%$ of Center Scholars, $79.9 \%$ of Average GPA students, and $85 \%$ of honors students. Although it is hard to validate whether or not students have used a library catalog or a research database, it is interesting to note that students report a similar level of familiarity with using library resources regardless of high school GPA.

\section{Pre-Test Scores: General Knowledge Questions}

Six of the questions on the pre-test that we analyzed were categorized as general knowledge questions including "Which response best describes a research database?," "Google is?," "An abstract 
is?," "A primary source document is?," "Failure to give credit to your sources of information is called?," and "APA and MLA style both refer to?"

Although we hypothesized that scores on general knowledge questions would vary based on high school GPA, we again found negligible differences among the three cohorts on the majority of general knowledge questions. On the questions asking students to identify the definition of a research database and a primary source document, there was a negligible difference between the scores of Center Scholars and Average GPA students, but honors students performed notably stronger. To further examine this pattern, we compared the total number of general knowledge questions that students answered correctly by running a one-way ANOVA comparing the three groups. The results showed that performance varied significantly between the groups, $F(2,713)=4.76, p=.008$; post hoc pairwise comparisons (Tukey HSD) between the groups found that honors students performed significantly better than both the Center Scholars $(p=.018)$ and Average GPA students $(p=.008)$, but no significant difference between the Center Scholars and Average GPA students ( $p=.880)$.

\begin{tabular}{|c|c|c|}
\hline Question & Cohort Group & Percentage correct \\
\hline \multirow{3}{*}{$\begin{array}{l}\text { Which response best describes } \\
\text { a research database? }\end{array}$} & Center Scholars & $54.1 \%$ \\
\hline & Average GPA Students & $57.2 \%$ \\
\hline & Honors Students & $70 \%$ \\
\hline \multirow[t]{3}{*}{ Google is? } & Center Scholars & $90 \%$ \\
\hline & Average GPA Students & $94.4 \%$ \\
\hline & Honors Students & $98.3 \%$ \\
\hline An Abstract is? & Center Scholars & $66.7 \%$ \\
\hline
\end{tabular}




\begin{tabular}{|c|c|c|}
\hline & Average GPA Students & $68 \%$ \\
\hline & Honors Students & $70 \%$ \\
\hline \multirow[t]{3}{*}{ A primary source document is? } & Center Scholars & $63.5 \%$ \\
\hline & Average GPA Students & $62 \%$ \\
\hline & Honors Students & $75 \%$ \\
\hline \multirow{3}{*}{$\begin{array}{l}\text { Failure to give credit to your } \\
\text { sources of information is } \\
\text { called? }\end{array}$} & Center Scholars & $96.4 \%$ \\
\hline & Average GPA Students & $95.2 \%$ \\
\hline & Honors Students & $95.1 \%$ \\
\hline \multirow{3}{*}{$\begin{array}{l}\text { APA and MLA style both refer } \\
\text { to? }\end{array}$} & Center Scholars & $94.1 \%$ \\
\hline & Average GPA Students & $94.7 \%$ \\
\hline & Honors Students & $100 \%$ \\
\hline
\end{tabular}

Table 1. General Knowledge Pre-Test Questions

\section{Pre-Test Scores: Performance Questions}

There were three questions on the pre-test that were categorized as performance questions.

Two of the performance questions required students to search the library database or catalog including "Using the database Academic Search Complete, search for college recycling. How many articles do you retrieve?," and "Use the library catalog to find the book Teaching First Year College Students. What is this book's call number?"

Although we had initially hypothesized that the differences in scores would be the smallest for the performance category, students' test scores on the performance questions actually revealed a greater difference between the scores of honors students and the Center Scholar and Average GPA cohorts. To further examine this pattern, we compared the total number of performance questions 
that students answered correctly on the pre-test by running a one-way ANOVA comparing the three groups. The results showed that performance varied significantly between the groups, $F(2,713)=14.90$, $p<.001$; post hoc pairwise comparisons (Tukey HSD) between the groups found that honors students performed significantly better than both the Center Scholars $(p<.001)$ and Average GPA students $(p<$ .001), but no significant difference between the Average GPA students and the Center Scholars ( $p=$ $.564)$.

\begin{tabular}{|c|c|c|}
\hline Question & Cohort Group & Percentage correct \\
\hline \multirow{3}{*}{$\begin{array}{l}\text { Using the database Academic } \\
\text { Search Complete, search for } \\
\text { college recycling. How many } \\
\text { articles do you retrieve? }\end{array}$} & Center Scholars & $12.9 \%$ \\
\hline & Average GPA Students & $22.2 \%$ \\
\hline & Honors Students & $55 \%$ \\
\hline \multirow{3}{*}{$\begin{array}{l}\text { Use the library catalog to find } \\
\text { the book Teaching First Year } \\
\text { College Students. What is this } \\
\text { book's call number? }\end{array}$} & Center Scholars & $52.9 \%$ \\
\hline & Average GPA Students & $52.4 \%$ \\
\hline & Honors Students & $71.7 \%$ \\
\hline
\end{tabular}

Table 2. Performance Pre-Test Questions

For the final performance question, students were given a hypothetical research question and asked to identify the most important keyword terms. The research question used was "What can colleges do to promote recycling on campus?" We assigned point values according to the importance of the term and deducted points for students who included "negative terms" such as "What" "can" "do" and "to." We determined that college and recycling were the two most important terms as the main theme of the question related to recycling at colleges. We determined that promote was the next most important term in helping students narrow down their search results. Points were assigned as follows: college(s), recycling (4 points); promote (3 points); campus (1 point if college(s) used, 3 points if college(s) not 
used; -2 points for all negative words. The maximum amount of points a student could earn was 12.

Students who identified the three most important keyword terms (college, recycling, and promote) achieved a score of 11 points. Students who also identified campus as a keyword term achieved a score of 12 points. Therefore, we considered scores of 11 or higher to be excellent, 9 or 10 to be good, 7 or 8 to be fair, and scores of 6 or below to be poor.

\begin{tabular}{|c|c|c|}
\hline Question & Cohort Group & Mean Score \\
\hline \multirow{3}{*}{$\begin{array}{l}\text { The inquiry question for my research } \\
\text { paper is, "What can colleges do to } \\
\text { promote recycling on campus?" } \\
\text { Please list the most important keyword } \\
\text { terms or main concepts of my inquiry }\end{array}$} & Center Scholars & 7.53 \\
\hline & Average GPA Students & 8.03 \\
\hline & Honors Students & 9.1 \\
\hline
\end{tabular}

Table 3. Performance Pre-Test Question: Identifying Keyword Terms

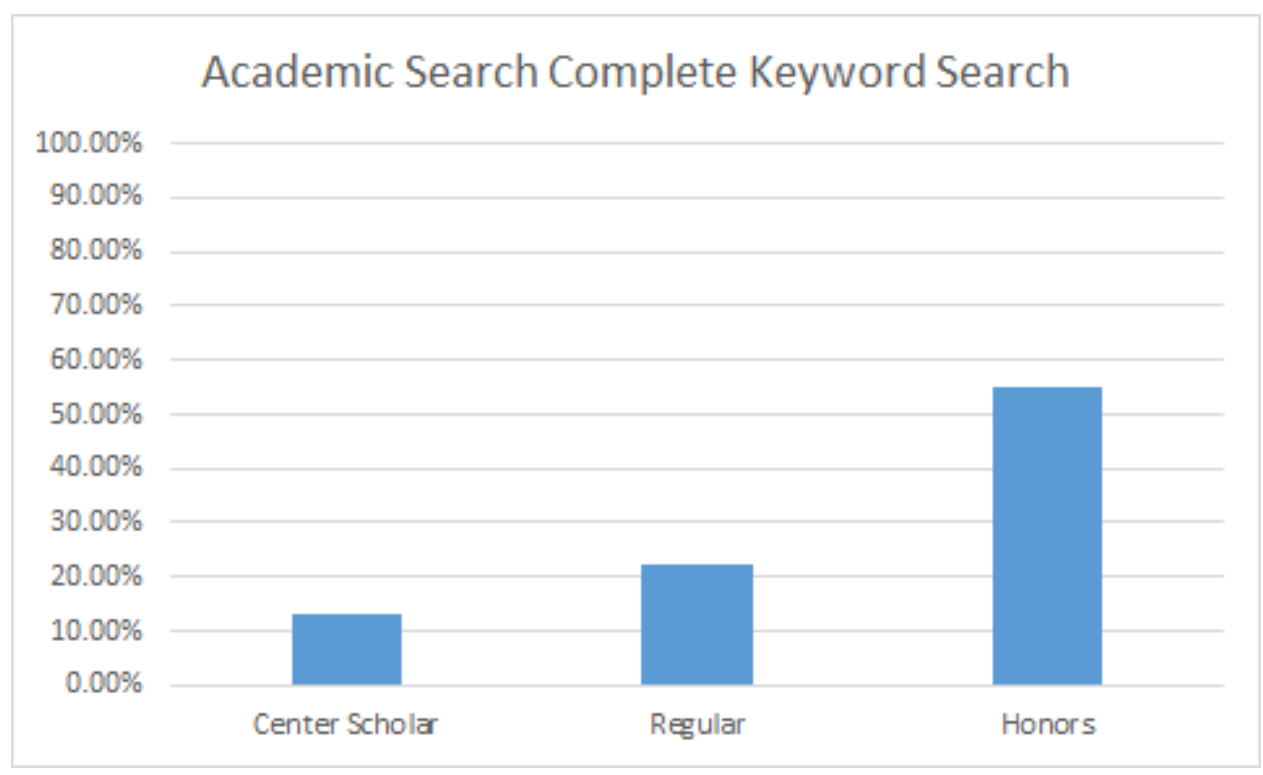

Figure 2. Pre-Test Performance Question Charts: Academic Search Complete 


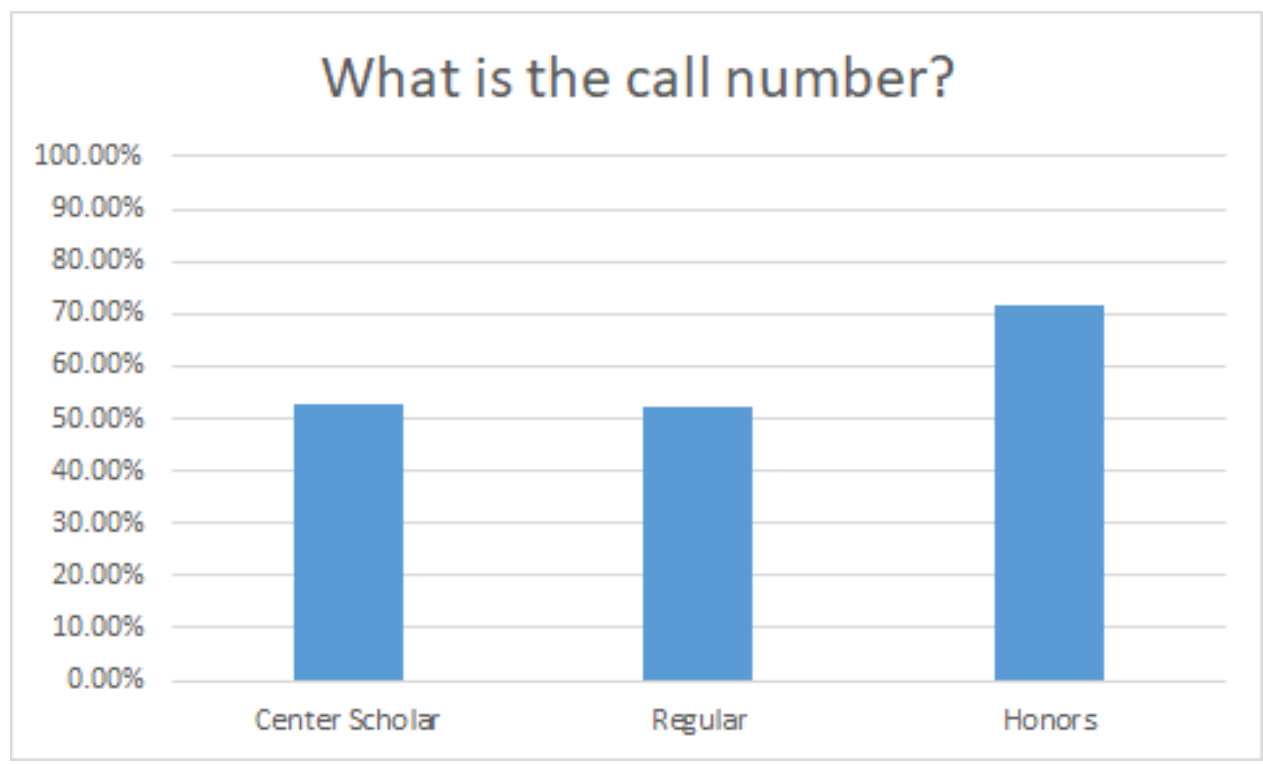

Figure 3. Pre-Test Performance Question Chart: Call Numbers

\section{Post-Test Scores: Self-Reported Responses}

Three questions on the post-test were categorized as self-reported responses. The three selfreported post-test questions differed slightly from the pre-test because we were seeking to gain additional data about student usage of library resources throughout the semester. These questions included "How many library instruction sessions have you attended this semester?," "Have you used a research database this semester?," and "Have you used the library catalog this semester?" As we saw with the pre-test, there were negligible differences among the three cohorts in their scores on the posttest. $42.5 \%$ of students reported attending two or more library instruction sessions throughout the semester including $42.9 \%$ of Center Scholars, $43.3 \%$ of Average GPA students, and $37.3 \%$ of honors students. $96.3 \%$ of all students reported having used a research database during the semester including $96.4 \%$ of Center Scholars, $95.9 \%$ of Average GPA students, and $98.4 \%$ of honors students. $66.4 \%$ of all students reported having used the library catalog during the semester including $64.3 \%$ of Center Scholars, $66.2 \%$ of Average GPA students and $70.3 \%$ of honors students. 


\section{Post-Test Scores: General Knowledge Questions}

The six general knowledge questions that were asked on the post-test were identical to those asked on the pre-test.

Although there were negligible differences for four of the general knowledge pre-test questions, the post-test scores revealed greater variance among the three cohorts, as both honors students and Average GPA students improved their scores while Center Scholars fared worse than they had on the pre-test on most of the general knowledge post-test questions. To compare performance between groups on the post-test we ran a one-way ANOVA comparing the total general knowledge questions that students answered correctly. The results showed that performance varied significantly between the groups, $F(2,583)=19.14, p<.001$; post hoc pairwise comparisons (Tukey HSD) between the groups found that honors students performed significantly better than both the Center Scholars ( $p$ $<.001$ ) and Average GPA students ( $p=.003$ ), while the Average GPA students performed significantly better than the Center Scholars $(p<.001)$.

We performed a 2 (pre-test/post-test) $\times 3$ (groups) ANOVA, using the regression method to account for the different numbers of students in the three groups. As expected, performance differed significantly by group and between the pre-test-and post-test for General Knowledge Questions: There was a significant main effect of group, $F(2,1296)=19.35, p<.001$, and a significant pre-test/post-test main effect, $F(1,1296)=4.78, p=.029$. There was also a significant pre-test/post-test $x$ group interaction effect, $F(2,1296)=5.26, p=.005$, reflecting that honors and Average GPA students performed better on the post-test than on the pre-test, but Center Scholars did not. 


\begin{tabular}{|c|c|c|}
\hline Question & Cohort Group & $\begin{array}{l}\text { Percentage correct } \\
{ }^{\star} \text { pre-test scores in parentheses }\end{array}$ \\
\hline \multirow{3}{*}{$\begin{array}{l}\text { Which response best describes } \\
\text { a research database? }\end{array}$} & Center Scholars & $66.1 \%(54.1 \%)$ \\
\hline & Average GPA Students & $79.2 \%(57.2 \%)$ \\
\hline & Honors Students & $79.7 \%(70 \%)$ \\
\hline \multirow[t]{3}{*}{ Google is? } & Center Scholars & $83.9 \%(90 \%)$ \\
\hline & Average GPA Students & $95.7 \%(94.4 \%)$ \\
\hline & Honors Students & $100 \%(98.3 \%)$ \\
\hline \multirow[t]{3}{*}{ An Abstract is? } & Center Scholars & $60 \%(66.7 \%)$ \\
\hline & Average GPA Students & $81.5 \%(68 \%)$ \\
\hline & Honors Students & $95.3 \%(70 \%)$ \\
\hline \multirow[t]{3}{*}{ A primary source document is? } & Center Scholars & $44.6 \%(63.5 \%)$ \\
\hline & Average GPA Students & $56.7 \%(62 \%)$ \\
\hline & Honors Students & $78.1 \%(75 \%)$ \\
\hline \multirow{3}{*}{$\begin{array}{l}\text { Failure to give credit to your } \\
\text { sources of information is } \\
\text { called? }\end{array}$} & Center Scholars & $92.9 \%(96.4 \%)$ \\
\hline & Average GPA Students & $97.2 \%(95.2 \%)$ \\
\hline & Honors Students & $100 \%(95.1 \%)$ \\
\hline \multirow{3}{*}{$\begin{array}{l}\text { APA and MLA style both refer } \\
\text { to? }\end{array}$} & Center Scholars & $96.4(94.1 \%)$ \\
\hline & Average GPA Students & $98.1(94.7 \%)$ \\
\hline & Honors Students & $100(100 \%)$ \\
\hline
\end{tabular}

Table 4. General Knowledge Post-Test Questions

The primary source document question was the only question that showed an overall decline between the pre-test and post-test scores. Primary source documents are not explicitly covered in the 
required FYI library instruction sessions, but Center Scholars' scores declined by nearly 20 percentage points on this question while Average GPA students' scores declined slightly, and honors students' scores showed a small improvement. One possible reason for this decline is that in college, students are introduced to different definitions of primary source documents depending on their major. For example, in the health sciences (and to a lesser extent, the social sciences), original research articles are considered primary sources. This alternate definition of a primary source may confuse students who entered college with a more clear-cut definition of what constitutes a primary source document. However, this still does not explain the steep decline in the scores of Center Scholars compared to Average GPA students.

We had originally hypothesized that Center Scholars would score lower on the general knowledge pre-test questions, but that they would close the gap on the post-test. The results reveal the opposite: Center Scholars had nearly identical scores as Average GPA students on the pre-test, but scored worse on most of the questions than they had on the post-test while Average GPA students and honors students improved their scores on all but one of the post-test questions.

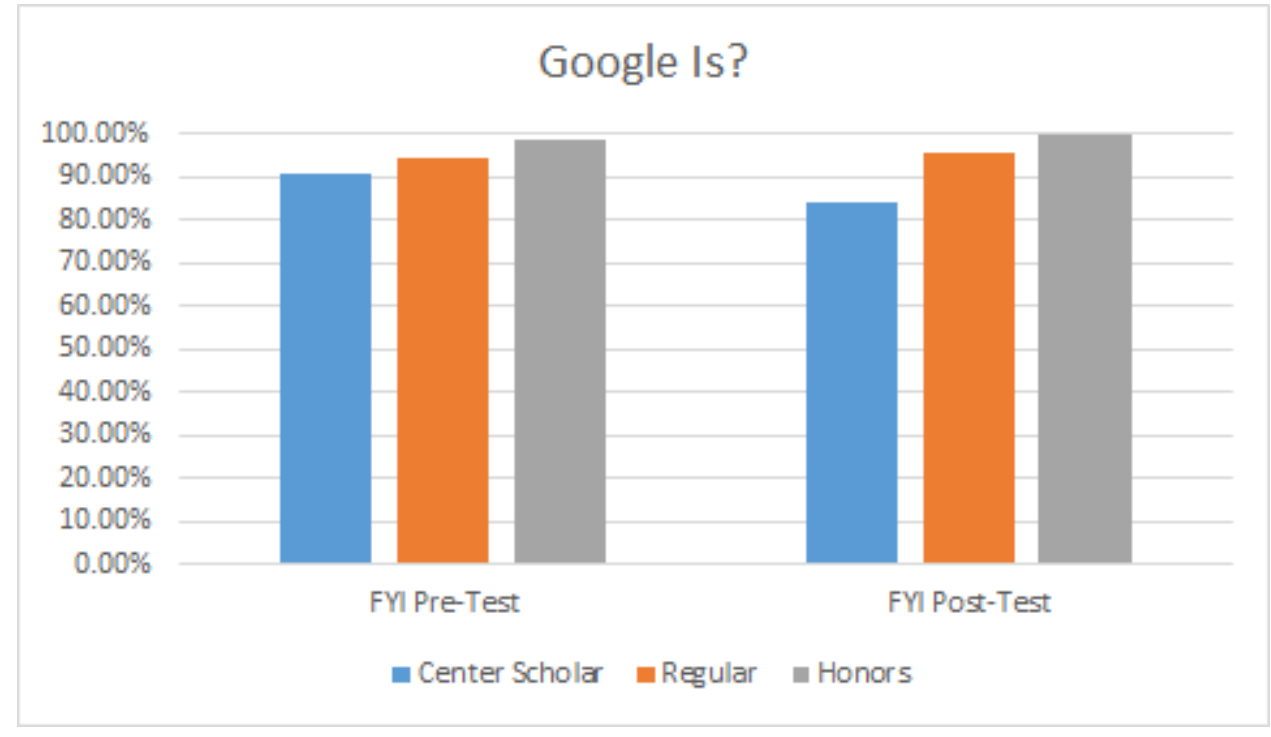

Figure 4. General Knowledge Questions Pre-Test and Post-Test Comparison Chart: Google 


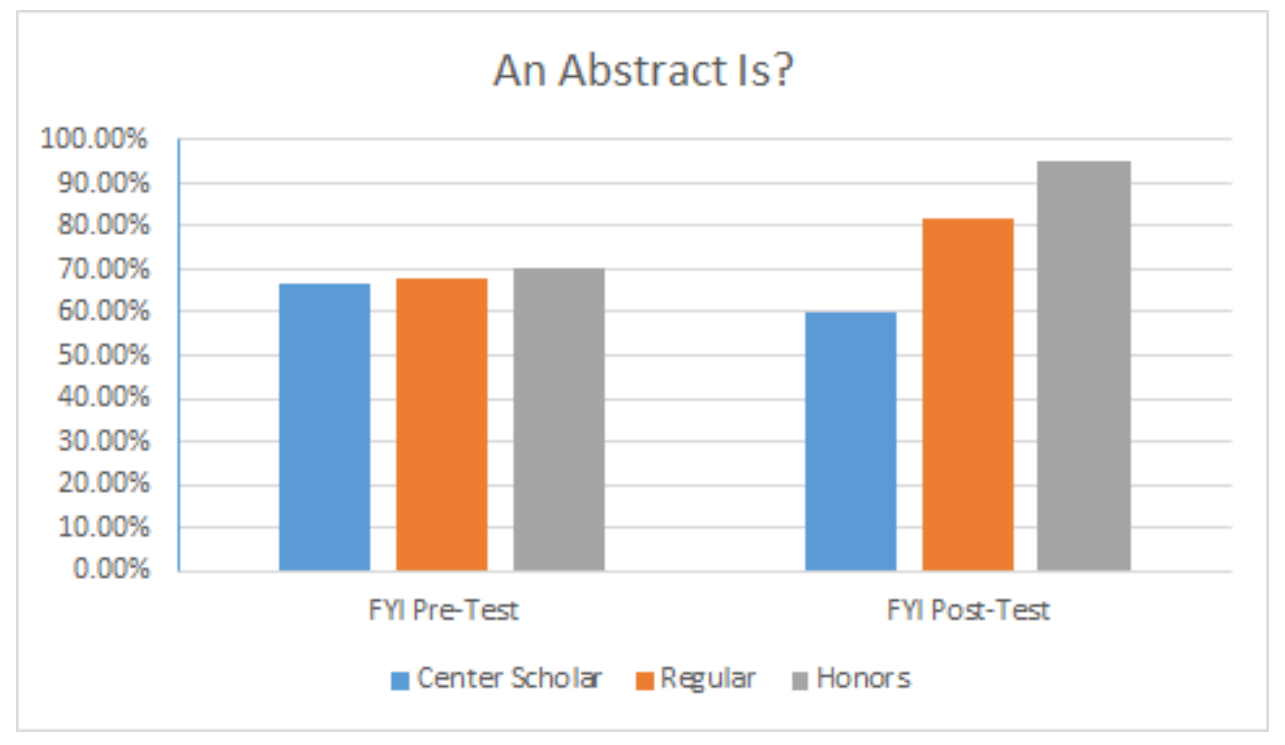

Figure 5. General Knowledge Questions Pre-Test and Post-Test Comparison Chart: Abstracts

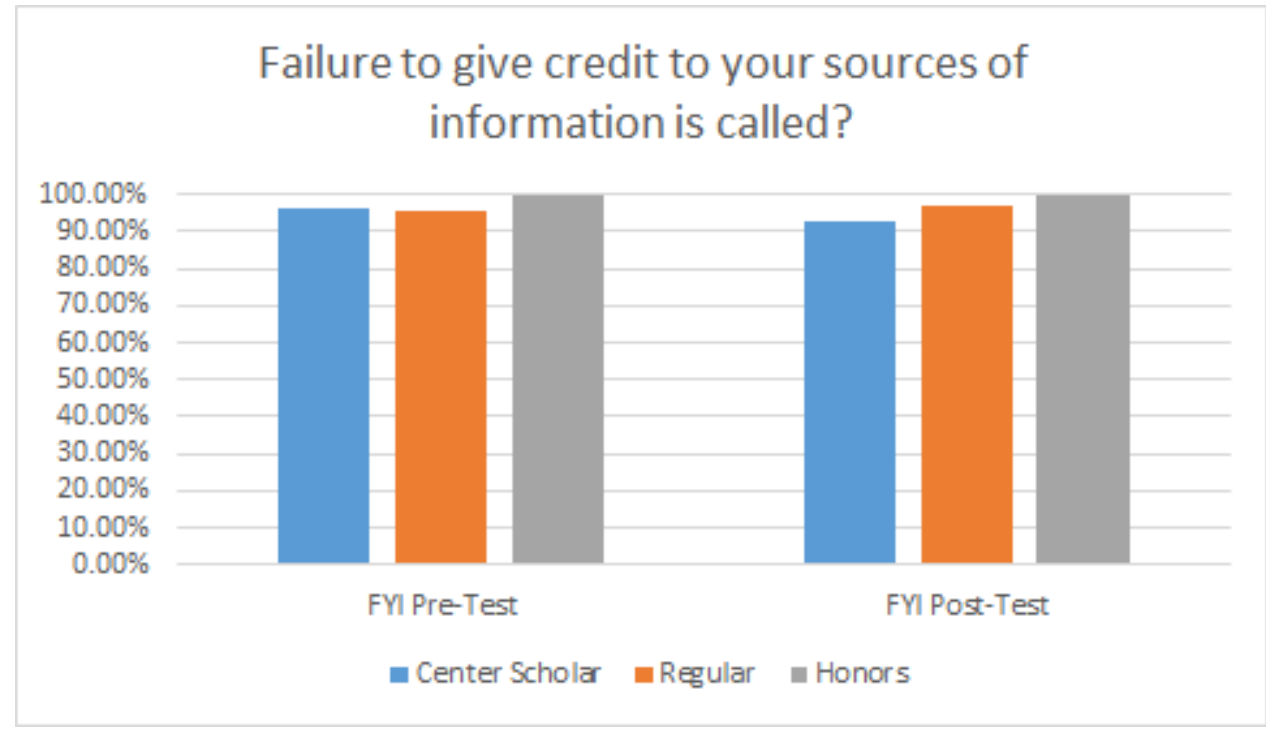

Figure 6. General Knowledge Questions Pre-Test and Post-Test Comparison Chart: Plagiarism 


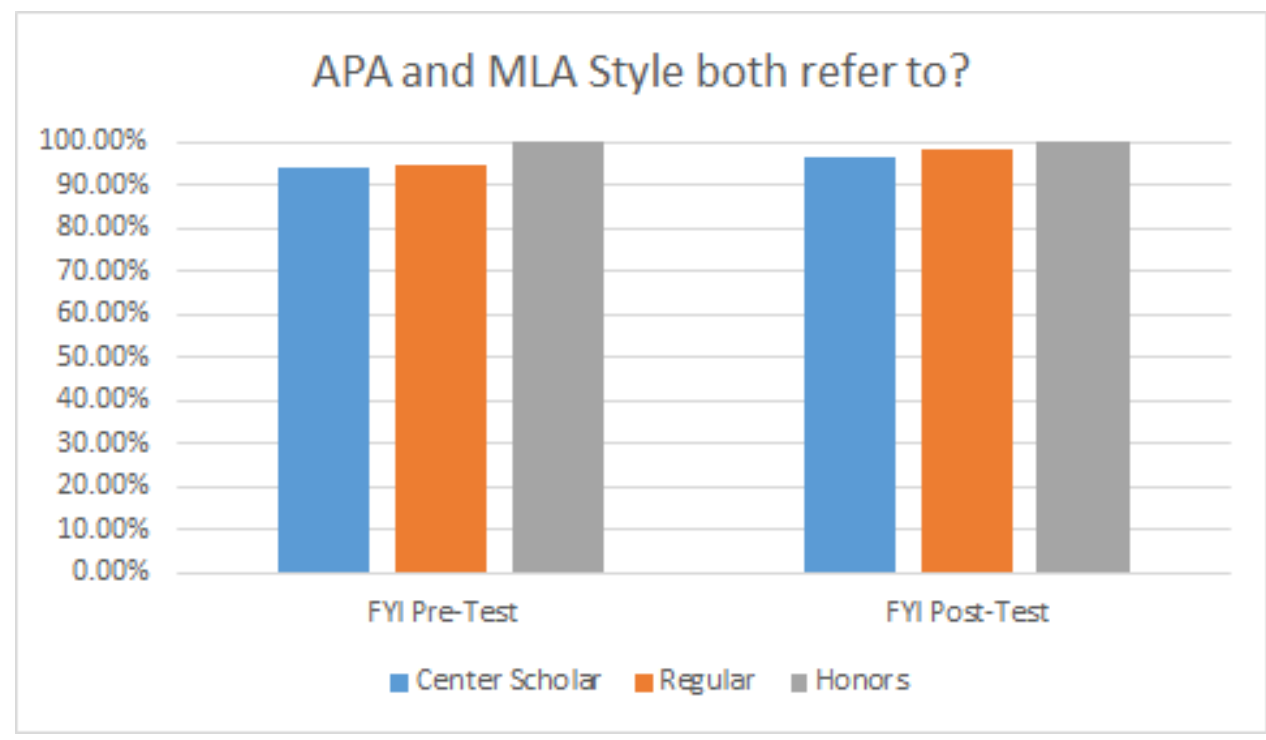

Figure 7. General Knowledge Questions Pre-Test and Post-Test Comparison Chart: Citation Styles

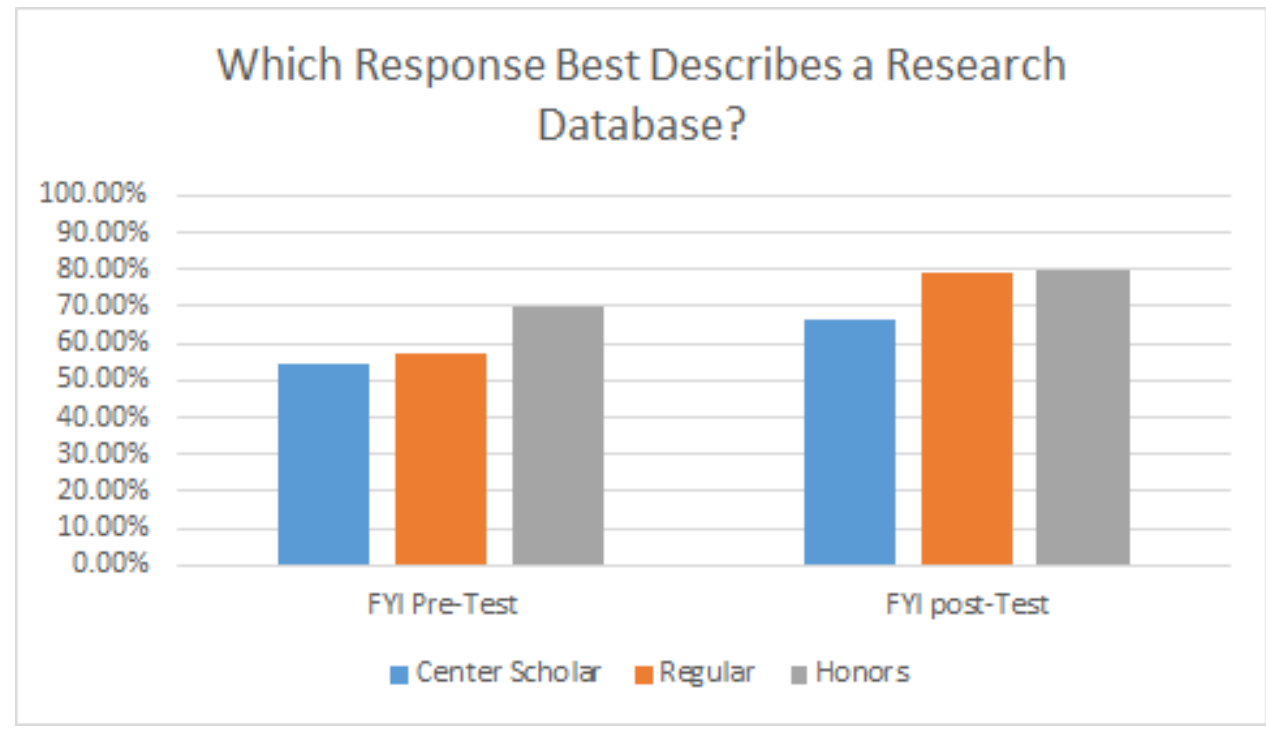

Figure 8. General Knowledge Questions Pre-Test and Post-Test Comparison Chart: Databases 


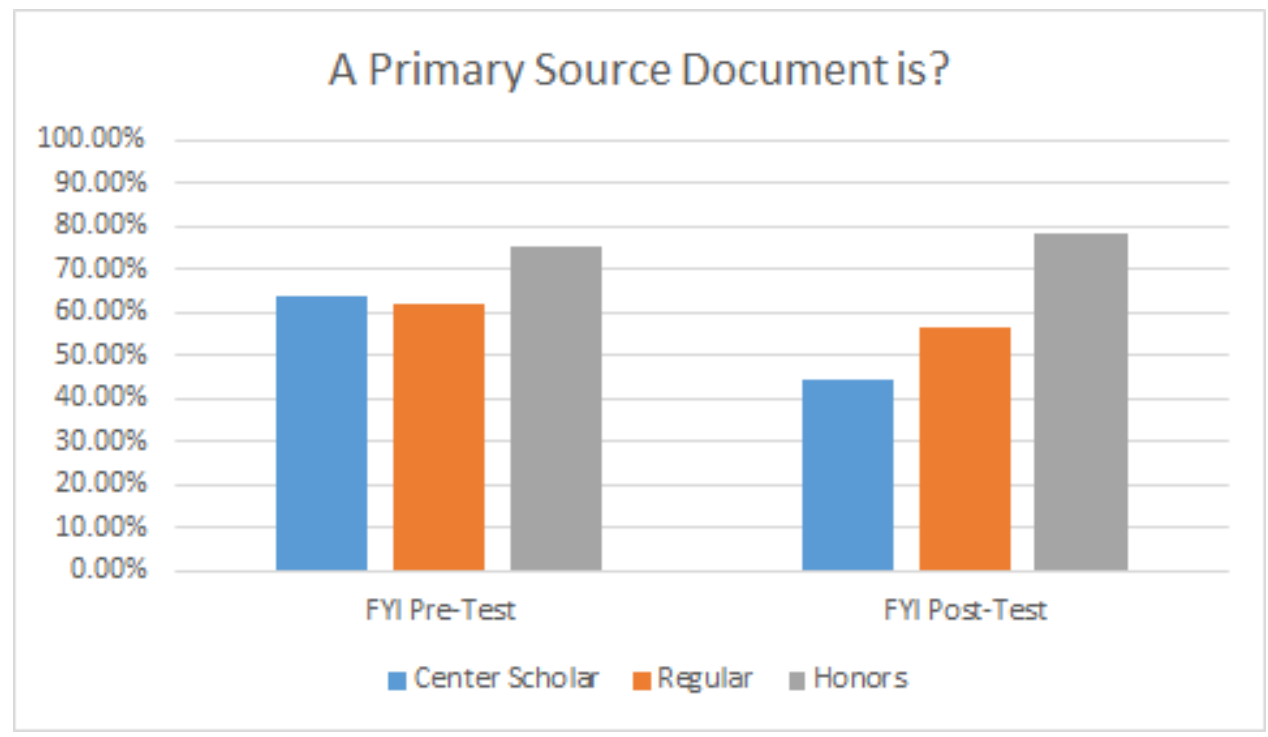

Figure 9. General Knowledge Questions Pre-Test and Post-Test Comparison Chart: Primary Sources

\section{Post-Test Scores: Performance Questions}

The three post-test performance questions asked students to perform the same tasks as the pre-test including performing a keyword search in Academic Search Complete and identifying the number of articles retrieved, searching for a book in the catalog and identifying its call number, and identifying the most important keyword terms of a research question.

Overall, students improved their test scores from the pre-test to the post-test on performance questions with honors students achieving the highest scores, followed by Average GPA students and then Center Scholars. To compare performance between groups on the post-test we ran a one-way ANOVA comparing the total performance questions that students answered correctly. The results showed that performance varied significantly between the groups, $f(2,583)=11.29, p<.001 ;$ post hoc pairwise comparisons (Tukey HSD) between the groups found that honors students performed significantly better than both the Center Scholars $(p<.001)$ and Average GPA students $(p<.001)$, while the Average GPA students performed significantly better than the Center Scholars $(p=.045)$.

We performed a 2 (pre-test/post-test) $\times 3$ (groups) ANOVA, using the regression method to account for the different numbers of students in the three groups. As expected, performance differed 
significantly by group and between the pre-test-and post-test: There was a significant main effect of group, $F(2,1290)=25.43, p<.001$, and a significant pre-test/post-test main effect, $F(1,1290)=30.86, p<$ .001. The pre-test/post-test $x$ group interaction effect was not significant, $F(2,1290)=1.29, p=.274$, reflecting that the difference between the pre-test and post-test performance did not vary between the three groups of students.

\begin{tabular}{|c|c|c|}
\hline Question & Cohort Group & $\begin{array}{l}\text { Percentage correct } \\
{ }^{\star} \text { pre-test Scores in } \\
\text { Parentheses }\end{array}$ \\
\hline \multirow{3}{*}{$\begin{array}{l}\text { Go to the library webpage and find the } \\
\text { library database Academic Search } \\
\text { Complete. Perform a } \\
\text { search for student drinking. How many } \\
\text { articles do you retrieve? }\end{array}$} & Center Scholars & $45.5 \%(12.9 \%)$ \\
\hline & Average GPA Students & $50.3 \%(22.2 \%)$ \\
\hline & Honors Students & $60.9 \%(55 \%)$ \\
\hline
\end{tabular}

Table 5. Post-Test Performance Questions

For the final performance question (see table 2), in which students were asked to identify the most important keyword terms of an inquiry question, we again assigned point values using the same criteria as the pre-test. The inquiry question used for the post-test was "What can colleges do to reduce alcohol on campus?" All cohort groups improved their scores on the post-test, but Center Scholars exhibited the lowest rate of improvement of the three cohorts.

\begin{tabular}{|c|c|c|}
\hline Question & Cohort Group & $\begin{array}{l}\text { Median Score } \\
\text { *pre-test scores in parenthesis }\end{array}$ \\
\hline \multirow{3}{*}{$\begin{array}{l}\text { The inquiry question for my research } \\
\text { paper is, "What can colleges do to } \\
\text { promote recycling on campus?" } \\
\text { Please list the most important keyword } \\
\text { terms or main concepts of my inquiry }\end{array}$} & Center Scholars & $8.03(7.53)$ \\
\hline & Average GPA Students & $9.8(8.03)$ \\
\hline & Honors Students & $10.2(9.1)$ \\
\hline
\end{tabular}

Table 6. Post-Test Performance Question: Identifying Keyword Terms 


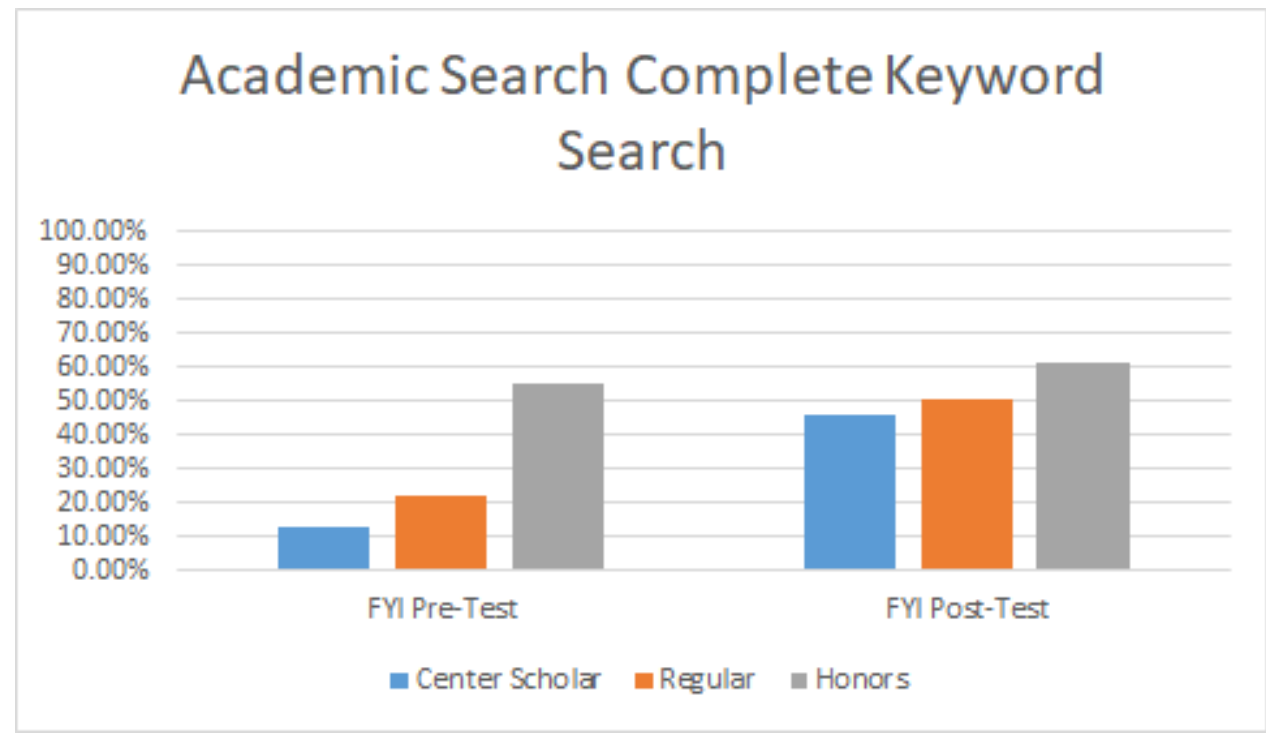

Figure 10. Pre-Test and Post-Test Comparison Chart: Academic Search Complete

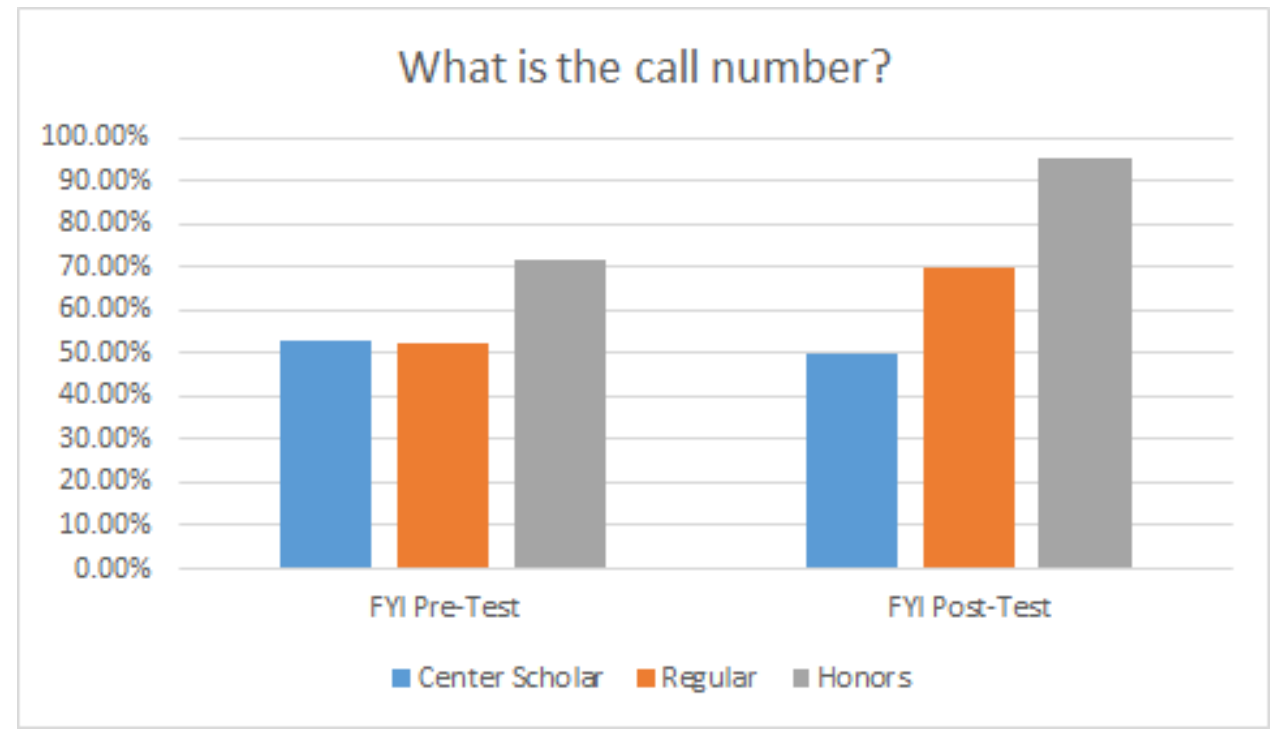

Figure 11. Pre-Test and Post-Test Comparison Chart: Call Numbers

\section{Discussion}

The results of this research study conflicted with our initial hypothesis that Center Scholars would struggle the most with general knowledge pre-test questions, but that they would improve in this area by attending a library instruction session and completing a research project as part of their First Year Inquiry class. Student scores revealed that there were negligible differences between Center Scholars and Average GPA students on both the self reported and general knowledge pre-test 
questions. Even honors students only performed marginally better than other students on two of the six general knowledge pre-test questions.

The performance pre-test questions, which we hypothesized would show the smallest differences among the three cohorts, in fact revealed the largest disparities in pre-test scores. Despite the fact that none of the incoming first year students had experience navigating our library's website, honors students were substantially better at navigating the website and figuring how to locate and search the catalog and database compared to both Average GPA students and Center Scholars. One explanation for the high performance of honors students is that they may have more experience with conducting research and navigating other library's websites compared to students entering college with lower high school GPAs. Another possible explanation is that the honors students were more determined to figure out how to navigate the website and find the databases and catalog while students with lower GPAs were not as self-confident in their ability to do so. More research should be conducted on the relationship between high school GPA and persistence in order to better understand the psychological component underlying test scores and academic performance.

Students' post-test scores also conflicted with our initial hypothesis that Center Scholars would make substantial improvements in their research skills over the course of the semester thus narrowing the score gap. The scores revealed that Center Scholars fared worse on many of the posttest questions and only made improvements on three of the questions that we analyzed. Center Scholars were the only cohort to have fared worse on more than one post-test question and only improved by an average of $1.03 \%$ per the eight questions that we analyzed (the six general knowledge questions and the catalog and database searching performance questions). Average GPA students improved by an average of $9.05 \%$ per question, while honors students improved by an average of 
$8.67 \%$ per question. Honors students, however, had the least room for improvement as their scores on the pre-test were the highest of the three cohorts.

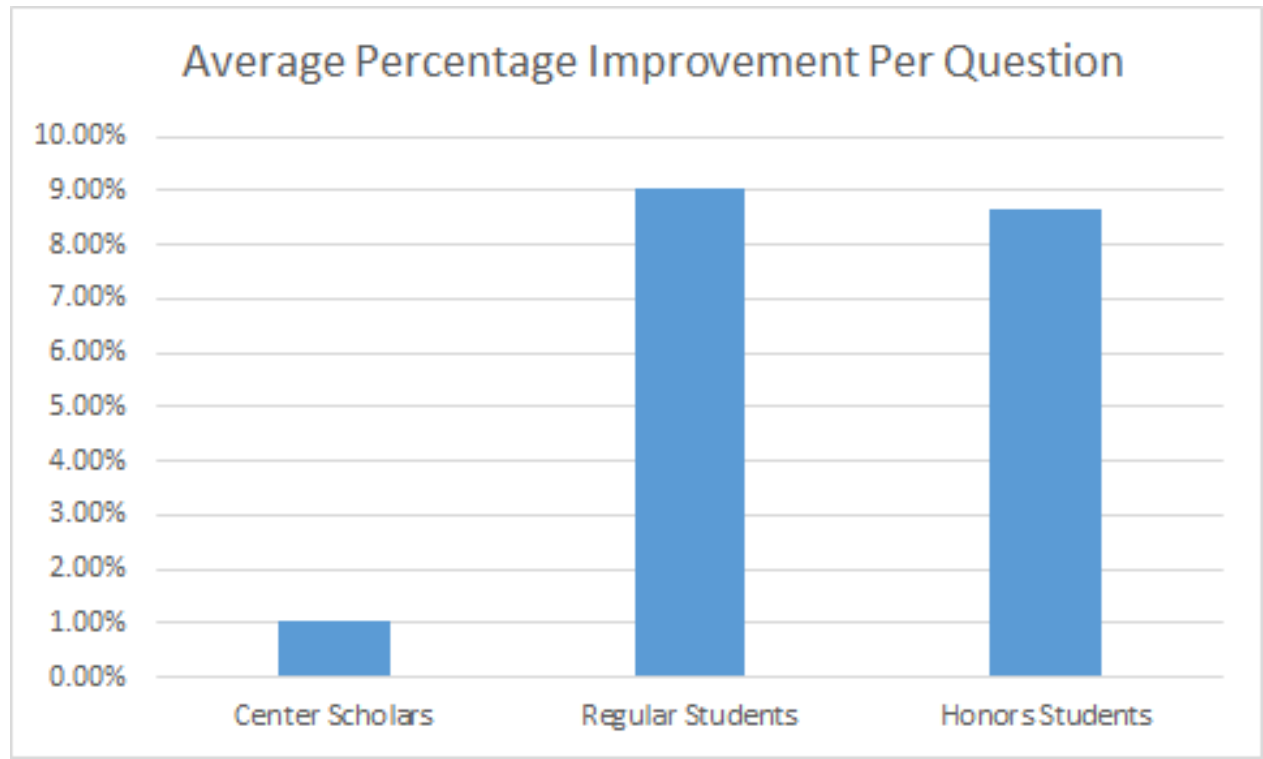

Figure 12. Improvement Rate Chart

The other large difference that we observed between the Center Scholars and the rest of the student body was in their low participation rate in both the pre and post-tests compared to Average GPA and honors students.

Although more research needs to be done to more fully understand the impact of high school GPA on information literacy test scores, our study provides some insight into the research skills and behavior of students who enter college with low high school GPAs. Center Scholars did not begin the semester with a large information literacy knowledge gap compared to their peers, but they did demonstrate a substantial enthusiasm gap as evidenced by their low participation rate on the pre-test. One possible explanation for Center Scholars' failure to improve may be that they are less likely than their peers to participate in assignments and maintain focus during class. As a result, they are not learning new information that is being taught during their first semester. 
Both the Knouse, Feldman and Blevins (2014) and the Hsieh, Sullivan and Guerra (2007) studies that were mentioned in the literature review reinforce our findings that non-cognitive attributes such as low executive functioning skills, goal setting, and self-efficacy may play a substantial role in the struggles that students entering college with low high school GPAs face. A difference in self-efficacy among the three cohorts could possibly explain why Honors students scored much higher than Average GPA students and Center Scholars on the performance pre-test questions. Honors students may exhibit a greater belief in their own abilities to successfully navigate the library's website and locate and perform searches in an academic database and library catalog, while students with lower levels of self-efficacy may psychologically shut down when confronted with questions that require them to perform an unfamiliar task. These differences in goal orientation could also help explain why students with lower incoming high school GPAs failed to improve their library research skills during the first semester while the rest of their peers made substantial improvements in their scores.

\section{Conclusion}

This study showed that the largest difference between Center Scholars and their peers was found in their post-test scores and not their pre-test scores. However, additional research needs to be done to see if our results can be replicated at other institutions. In addition, this study did not provide a clear-cut explanation for these results. More data needs to be collected in order to answer the following questions: Do students with low GPAs at other institutions show similar declines (or low rates of improvement) across the course of the semester on library research skills assessments? And, if so, what are the reasons behind these declines when compared to their peers? Prior research on executive functioning, self-efficacy, and goal orientation have explored non-cognitive attributes that affect academic success among college students, but further research should be done to explore the possible relationships between executive functioning skills, high school GPA, and performance on 
library research skills pre and post-tests. These are important issues for Colleges and Universities to explore in order to improve retention of at-risk incoming first year students and to ensure the academic success of the students that they admit.

\section{References}

Barkley, R. A. (2012). Barkley deficits in executive functioning scale--children and adolescents (BDEFSCA). Guilford Press.

Fabbi, J. L. (2015). Fortifying the pipeline: A quantitative exploration of high school factors impacting the information literacy of first-year college students. College \& Research Libraries, 76(1), 31-42.

Gaha, U., Hinnefeld, S., \& Pellegrino, C. (2018). The academic library's contribution to student success: Library instruction and GPA. College \& Research Libraries, 79(6), 737.

Geffert, B., \& Christensen, B. (1998). Things they carry: Attitudes toward, opinions about, and knowledge of libraries and research among incoming college students. Reference \& User Services Quarterly, 279-289.

Gross, M., \& Latham, D. (2007). Attaining information literacy: An investigation of the relationship between skill level, self-estimates of skill, and library anxiety. Library \& Information Science Research, 29(3), 332-353.

Hsieh, P., Sullivan, J. R., \& Guerra, N. S. (2007). A closer look at college students: Self-efficacy and goal orientation. Journal of Advanced Academics, 18(3), 454-476.

Knouse, L. E., Feldman, G., \& Blevins, E. J. (2014). Executive functioning difficulties as predictors of academic performance: examining the role of grade goals. Learning and Individual Differences, $36,19-26$.

Lanning, S., \& Mallek, J. (2017). Factors influencing information literacy competency of college students. The Journal of Academic Librarianship, 43(5), 443-450. 
Mahmood, K. (2013). Relationship of students' perceived information literacy skills with personal and academic variables. Libri, 63(3), 232-239.

Mayer, J., \& Bowles-Terry, M. (2013). Engagement and assessment in a credit-bearing information literacy course. Reference Services Review, 41(1), 62-79.

Wong, S. H. R., \& Cmor, D. (2011). Measuring association between library instruction and graduation GPA. College and Research Libraries, 72(5), 464 


\section{Appendix A}

Go to First Year Resources: FYI Lib Guide

\section{1.) Inquiry Question Tab}

Write down the inquiry question that you have prepared for class. Underline the main concepts of your question:

\section{2.) Background Tab (Tertiary)}

Where would you find background information and why?

\section{3.) Library Catalog Tab}

Find a book in the library's catalog related to your research question.

Book Title:

Call Number:

Author:

Date:

Publisher:

Place:

Is it available in the DiPietro Library? If not, how do you request it?

\section{4.) Keywords Tab}

Pick two of the main concepts of your question and come up with alternative keywords for them:

\begin{tabular}{|l|l|l|l|l|}
\hline Terms & & & & \\
\hline Broader & & & & \\
\hline Narrower & & & & \\
\hline Synonyms & & & & \\
\hline
\end{tabular}




\section{5.) Article Databases Tab (Secondary/Primary)}

Find an article in a either ASC or ProQuest related to your topic.

Article Title:

Author:

Journal:

Date: 